\title{
IMAGEN CARTOGRÁFICA DE SUDAMÉRICA. ESTRUCTURA Y FACTOR HIDROGRÁFICO
}

\author{
Mariano Cuesta Domingo \\ Universidad Complutense de Madrid
}

\section{RESUMEN}

La estructura del continente explica la situación del hombre y, del mismo modo, puede afirmarse que el factor hidrográfico jugó un papel primordial en la exploración de los espacios y territorios. Estos condicionamientos juntamente con otros condicionantes, explican la sistemática exploratoria, la descripción y el control del interior continental.

PALABRAS CLAVE: América del Sur, exploración, cartografía.

\section{ABSTRACT}

The structure of the continent explains the situation of men and, likewise, it can be said that the hydrographic factor played an important role in the exploration of spaces and territories. These constraints, along with other conditions, explain the systematic exploration, description and control of the continental interior.

KEYWORDS: South America, exploration, cartography. 
Es evidente que la estructura de un continente ofrece alguna explicación al estado de su población humana en tiempos históricos y no es menos cierto que el factor hidrográfico jugó un rol destacado en los descubrimientos sobre los mismos espacios realizados por agentes foráneos. Esta realidad geográfico histórica, conjuntamente con otros condicionantes ambientales, ofrecen algún esclarecimiento a la sistemática exploradora inmediata así como a la descripción y control del interior continental. Por lo que respecta al subcontinente de América del Sur parece que las pautas se cumplen. Procedemos a una verificación bajo los epígrafes: 1. Disposición de América del Sur. 2.- La línea litoral.- 3. Sondeo continental. Explorando el Amazonas en ambos sentidos. Otros exploradores y viajeros.- 4. La región orinoco-guayanesa.- 5. Testimonio cartográfico.- 6. La estructura fluvial y el reconocimiento continental en el área más conflictiva.

Esta secuencia tiene por objetivo observar el rol jugado por la descripción y ordenación del territorio por la náutica hispánica, particularmente de la vertiente atlántica continental. Los hechos, lo experimental, y también lo especulativo fueron trasladados a los mapas y constituyen un testimonio histórico suficientemente estable, no en balde, como dijo Mercator, los mapas son las ventanas de la Historia.

\section{DISPOSICIÓN DE AMÉRICA DEL SUR}

A este respecto, la estructura de Sudamérica ha jugado un papel clave en tiempos posteriores al avistamiento continental colombino en su tercer viaje y a su inmediato contacto físico ${ }^{1}$; por entonces (15 de agosto de 1498) el Almirante escribió a los Reyes Católicos unas líneas que constituyen un testimonio de su ignorancia sobre el territorio costero que recorrían pero también muestran su convicción de hallarse por vez primera ante tierra continental: Yo creo que éste es un gran continente, "tierra firme grandísima", desconocido hasta hoy, pues de él desemboca una gran cantidad de agua dulce..., además expresaba otras consideraciones arcaizantes que le hacían rememorar otros textos y le condujeron a pensar que en aquellas tierras estaban, si no eran, el Paraíso Terrenal e incluso, apuntaba una teoría sobre la no esfericidad de la Tierra; sobre ella pensaba que el planeta tenía un perfil piriforme, lo que tampoco deja de tener su interés.

Las descripciones geográficas seguían los modelos habituales en los avistamientos y visitas a mundos desconocidos; la explicación inmediata utilizaba con profusión el sistema de trasladar las ideas que portaban a lo novedoso; seguía un método comparativo al hablar de la flora y de la fauna, del clima y del paisaje; realizaban interpretaciones generalizadoras al tratar de mostrar lo indígena, su cultura; invenciones y deturpaciones al imponer o adaptar una toponimia²; tenían gran proclividad a ver gigantes, buenos salvajes o antropófagos, utopías y quimeras y todo lujo de fantasías pero también daban a conocer cuestiones de sencilla cotidianeidad o a localizar peligros o puntualizar lugares acogedores.

\footnotetext{
1 Puede afirmarse que antes del tercer viaje colombino no tuvo tanta relevancia especial como los otros realizados por Colón, por más que la afirmación pueda dar lugar a debate.

2 CUESTA DOMINGO, M. y M. MURIEL: Atlas toponímico extremeño-americano. $3^{\mathrm{a}}$ ed. Madrid, ICI, 1992 [1 $1^{\text {a }}$ ed. Caja Badajoz, 1885]; CUESTA DOMINGO, M., los siguientes: "Presencia de España en Norteamérica. Panorama toponímico", en Bol. de la Real Sociedad Geográfica, CXXII (1989), pp. 93-108; "Imagen cartográfica de Filipinas y su entorno; testimonio toponímico", en El lejano Oriente español: Filipinas ( siglo XIX), Sevilla. Cátedra "General Castaños", 1997, pp. 2-38; "The long route of Santiago. Influence of the Apostle James in the Americas", en E. Martínez y M. de P. Pi (coord.): Scandinavia, Saint Brigitta and the Pilgrimage Route to Santiago de Compostela, Santiago de Compostela, 2002.
} 
Pero en una década prodigiosa se descubrió y describió con cierta minuciosidad un mundo que se consideró "mediterráneo", multi insular, de dimensiones análogas a las de mares y tierras de procedencia de los protagonistas. Un tiempo en que se percibió algo más turbador: las dimensiones colosales que parecían alargarse sin fin hacia el Sur. Américo Vespucio interpretó que se trataba de la Quarta orbis pars y eso le dio más fama, incluso, que a Colón merced al entusiasmo que despertó en Waldseemüller y éste último trasladó en su Cosmographia introductio $(1509)^{3}$.

Era un amplio territorio que se iba conociendo en su epidermis. Desde el golfo de Urabá hasta sobrepasar la desembocadura del río Amazonas, fue reconocida de forma táctil; un gran espacio con una notable diversidad de climas, de paisajes dispares pero de patrones de asentamiento humano y desarrollo cultural no muy diferentes. Había sin embargo algunos elementos destacables que fueron emergiendo: desde el punto de vista geopolítico estaba por marcar sobre el mapa la línea de Tordesillas; sobre el territorio nunca se hizo. Desde lo puramente geográfico, las desembocaduras de grandes cuencas fluviales, lo que significaban eventuales terminales de vías de acceso hacia el interior.

A este respecto es preciso recalcar el viaje de Díaz de Solís (1515) como el precedente inmediato del de Magallanes-Elcano (1519...) en el hallazgo del fin meridional del Nuevo Mundo, de América del Sur. Se había verificado el tamaño y la heterogeneidad de la ribera atlántica. Era un estímulo más para los protagonistas; enseguida se vieron persuadidos por otro no menor: la magnitud de la superficie continental (sucesivos y más complejos resultaron los alicientes que emergieron en el interior de aquellos territorios que casi duplicaban en extensión a los de toda Europa).

La visión del interior continental para aquellos descubridores náuticos fue muy corta, extraordinariamente precaria; carecían de medios y capacidad para adentrarse tierra adentro; su mirada percibía paisajes diversos que se cerraban por sierras andinas septentrionales (Sierra Nevada de Santa Marta) o que se abrían en amplias llanuras aluviales (Magdalena), con un medio poco hospitalario, carente de alicientes económicos y una población aborigen escasa y dispersa que imposibilitó un desarrollo urbano temprano. Más al oriente aparecían litorales desérticos áridos y, siguiendo la línea de costa hacia el sur comenzaron gigantescas llanuras litorales fangosas, selváticas, cálidas y húmedas, en que aparecer enormes deltas (Orinoco y grandes manglares (Guayanas) hasta alcanzar la inmensa y compleja desembocadura amazónica. Nuevamente hubo que recorrer grandes distancias hasta alcanzar el colosal estuario del Plata y, más al sur, nuevos paisajes y considerables distancias hasta poder dar fin a aquella fachada atlántica americana y dar comienzo al recorrido europeo del Mar del Sur.

En tiempos coetáneos se había fundado Panamá que se constituyó en el centro inicial del descubrimiento del Pacífico sudamericano. Fue un recorrido efectuado en dos décadas que vino a completar la figura periférica del subcontinente. Las características geográficas presentan similitudes pero las demográficas y culturales muestran diferencias ostensibles; los alicientes fueron suficientes para la Corona como para desarrollar una acción exploradora, fundadora y colonizadora que fue ampliando horizontes geográficos y expandiendo la frontera desde la vertiente pacífica hacia la atlántica; los incentivos no lo fueron tanto para los inversores.

3 Universidad Complutense [UCM], Biblioteca Histórica [BH], signatura [FG 2131]. 


\section{LA LÍNEA LITORAL}

No obstante se había alcanzado territorio continental y tras aquella derrota colombina (que hizo el recorrido lineal de la península de Paria desde el golfo homónimo) numerosas naves, siguiendo su estela, a impulsos de los mismos vientos, organizadas en múltiples expediciones, tallaron con la proa de sus barcos el perfil costero de América del Sur en diversas singladuras. Son bien conocidas las expediciones de Alonso de Ojeda, Juan de la Cosa y Américo Vespucio (1499-1500) recorrieron desde el cabo Orange, en Guayanas, hasta el cabo de la Vela, en la Goajira. La de Pero Alonso Niño y Cristóbal Guerra (1499-1500) haciendo una ruta más corta sobre la misma área (desde el brazo septentrional del delta del Orinoco hasta el punto, también venezolano, de Chuchiviriche). La expedición de Vicente Yáñez Pinzón (1499-1500) aportó el conocimiento de tierras más meridionales: desde el brasileño cabo de San Roque para navegar hacia el norte pasando por las bocas del Amazonas y del Orinoco; el mapa de Juan de la Cosa de 1500 ya ofrece los frutos geográficos de este viaje, del mismo modo que testimonia el paso de Diego de Lepe con su anotación "tierra donde se falló una cruz". De carácter análogo y recorrido continental mucho menor fue el viaje de Vélez de Mendoza y Luis Guerra (1500-1501), que reconoció la actual costa brasileña desde el cabo San Roque, sobrepasando la desembocadura del río San Francisco hasta la bahía de Todos los Santos. El viaje de Rodrigo de Bastidas y Juan de la Cosa (1501-1502) conoció la actual costa colombiana desde la península de Goajira hasta el golfo de Urabá. Finalmente, Américo Vespucio (1501-1502) trazó una derrota análoga a la de Vélez de Mendoza y Luis Guerra, el año anterior, y progresó hacia el sur hasta un lugar discutido de la costa sudamericana: unos piensan que no sobrepasó Bahía, otros que llegó al Río de la Plata y hay quien opina que alcanzó el puerto de San Julián. Unos años después (1515-1516), Juan Díez de Solís visitó precisamente la costa desde el cabo de San Roque hasta el Río de la Plata. En todo caso hubo que esperar hasta 1519 (Magallanes) para que el perfil costero atlántico de América del Sur se viera completado.

Por el contrario, la representación de la costa del "Mar del Sur" fue, obviamente, posterior pero más rápida y objeto de menor número de protagonistas; menos gravosa para la Corona, autosuficiente y mucho más rentable: es el fruto de los viajes de Pascual de Andagoya (1522), Pizarro y sus socios (1524-1532), Almagro (1535-1536) y otros sobre latitudes más meridionales que, como las septentrionales, fueron generalmente más tardías ${ }^{4}$.

Ante aquella inmensidad, en un ámbito desconocido, el calado de las embarcaciones constituía un factor de seguridad o podían convertirse en un mecanismo de catástrofe. La carabela seguía mostrándose como elemento técnico idóneo. Pero las expediciones eran escasas en efectivos ${ }^{5}$ y escuálidas en medios como para aventurarse a una penetración continental con muchas posibilidades de quedar diluidos, desaparecidos, se diría

4 Una aproximación en MORALES PADRÓN, Francisco: Atlas Histórico Cultural de América. Tomo I. Las Palmas de Gran Canaria, 1988; ver además VV.AA.: Historia naval brasileña. Vol. I, tomos I y II. Río de Janeiro, Ministerio da Marinha, 1975; asimismo en las Historias navales de todos los países con fachada pacífica.

5 Salvo tres especiales (segunda de Colón, la de Nicolás de Ovando y la de Pedrarias Dávila) que lo fueron con otras características. CUESTA DOMINGO, Mariano: "Tres armadas desestabilizadoras y una cuestión de honor", en Homenaje al prof. Dias Farinha. Lisboa, 2013. 
ahora. La actividad de grupos de conquistadores, en expresión de Góngora, evidenció la implacable dureza del medio noroccidental sudamericano así como a sus curtidos y aguerridos pobladores. Fue una sistemática caracterizada por el ensayo y el error.

\section{SONDEO CONTINENTAL}

La exploración del Amazonas es permanente. Pero el contacto foráneo inicial fue realizado cuando Vicente Yáñez Pinzón pasó por delante de la desembocadura del Río Grande (1500). El hecho quedó registrado en los mapas aunque no se prestó atención especial al descubrimiento del río porque carecía de atractivo alguno en aquel tiempo. La verdadera corriente exploradora que desveló el Amazonas se movió de Oeste a Este, siguiendo el curso de sus aguas, mediante extraordinarias navegaciones fluviales; fueron unas expediciones que tenían el objetivo de ampliar los horizontes geográficos hispanos pero también permitían liberar energías sobrantes de la conquista del mundo incaico mediante exploraciones en todas direcciones, tras alicientes míticos o legendarios como el País de la Canela, el Dorado o las Amazonas u otros más. Mitos con aires de certeza o fantasía con notas de leyenda constituyeron siempre un poderoso aliciente en las exploraciones y en la del Amazonas tanto o más que en ninguna otra.

Tras la de Díaz de Pineda (1538), bien provista aunque infructuosa, la expedición hacia el Oriente comenzó a fines de 1540, fue la protagonizada por Gonzalo Pizarro y Francisco de Orellana ${ }^{6}$.

El viaje fue atroz. Atravesaron la región de los quijos sufriendo mal de altura y fríos extremos, superando una topografía intrincada que imprimía gran lentitud a su marcha e incluso soportaron algún temblor. El descenso de la Sierra hacia el Amazonas no aminoró las dificultades ni atenuó sus angustias. El calor iba en aumento hasta hacerse asfixiante, los envolvía una atmósfera permanentemente húmeda y la fatiga se incrementaba; todavía Francisco de Requena, en 1777, describió aquellos caminos, sus asperezas y peligros como "insuperables para la tropa" y arriesgados para la navegación ${ }^{7}$. Hallaron un arbusto semejante a la canela pero nada rentable; no podía explotarse comercialmente por dificultades de transporte, escasa concentración de los árboles productores y baja calidad del producto. Agotados y hambrientos, los protagonistas alcanzaron el río $\mathrm{Coca}^{8}$.

La expedición se dividió en dos. Gonzalo Pizarro, fracasado, con una facción pudo retornar a Quito; en cambio Orellana protagonizó el viaje más extraordinario efectuado en este período a través del continente americano. En el "San Pedro", con 56 españoles, entre ellos el dominico y cronista de la epopeya fray Gaspar de Carvajal, inició su navegación (26, diciembre, 1541) por el río Coca hacia el Napo. El retorno, imposible;

6 La hueste debió ser todo un espectáculo, estaba compuesta por un lucido grupo de 350 españoles, 4.000 indios, 150 caballos, numerosos perros, abundantes pertrechos y provisiones, con una despensa viva formada por una piara de cerdos la cual, dudosamente, alcanzaría la cifra de 5.000 que cita el cronista Herrera. 7 Mapa Q-7-207. Centro Geográfico del Ejército, Madrid.

8 Este río y los sucesivos que navegaron no daban mayores facilidades a una marcha que parecía conducir a ninguna parte a través de un "desierto verde". Se planteó el dilema de avanzar o retroceder y entre dos males se eligió el que parecía menor: construyeron una barcaza con estilo pretencioso y hasta con nombre propio, seguramente buscando alguna protección bajo su advocación, y procedieron a efectuar una descubierta en busca de auxilios. 
avanzar hacia el mar, era la única alternativa. Construyeron una barcaza más y llegaron al río Grande, de Orellana o Marañón ${ }^{9}$.

El descenso fue relativamente fácil y cómodo en cuanto a esfuerzo físico se refiere, pero lamentable a causa del calor, la humedad, los insectos y demás penalidades así como al hostigamiento indígena permanente. Atravesaron territorio de los Omaguas y su cacique les anunció la existencia de riquezas que hallarían más lejos, naturalmente, y de la portentosa presencia de las caniapuyara o grandes señoras, blancas, altas... desnudas..., de largas cabelleras, armadas con arcos y flechas... tan aguerridas que cada una combatía como diez indios. Pasaron ante las bocas de importantes afluentes y lucharon contra un grupo en el que participaron mujeres guerreras ${ }^{10}$; por todo ello el Río fue nombrado Grande de las Amazonas. Finalmente salieron al Atlántico (26, agosto, 1542) dejando la isla de Marajó (de más de $40.000 \mathrm{Km}^{2}$ al sur). Desde allí Francisco de Orellana, vía Venezuela, Santo domingo, Azores arribó a España.

El viaje, efectuado como proyección de la conquista peruana, resultó el mayor de descubrimiento continental. Había servido para valorar la magnitud de América del Sur aunque desde el punto de vista económico concluía sin atractivo alguno si se exceptúa el interés cultural y geográfico. El testimonio del dominico Gaspar de Carvajal ${ }^{11}$ permite reconstruir un derrotero de aquella portentosa navegación, ríos con los que confluían, crecidas y turbulencias, extravíos, asentamientos indígenas, intercambio de obsequios y vacíos de población, dificultad de abastecimiento, improvisación y lucha por la supervivencia, penalidades y magulladuras. Verificaron el famoso "encuentro de las aguas" del río $\mathrm{Ne}$ gro con el Amazonas que tanto atrae a los turistas del siglo XXI, y pasando la confluencia con el río Madeira. Finalmente, Orellana hizo amarrar las dos embarcaciones, al borde de una isla, en la entrada del río Tapajoz; allí percibieron el efecto de las mareas sobre las aguas fluviales; el temible mar era esperado con una contradictoria ansiada expectativa.

Como el Orinoco, el Marañón con más razón llamó la atención de aventureros, ambiciosos y religiosos; coincidiendo con la época filipina portuguesa se difundieron noticias por Europa que atrajeron sobre aquella vasta región a gentes variadas. La ciudad de Manoa y el lago de Parime. Las primeras noticias y descripciones se vieron enriquecidas con las de otros tales como Diego de Acuña, Claude d'Abbeville, Francisco Caldera. Política y estratégicamente importaba la presencia de extranjeros en el final del curso del Amazonas; los acontecimientos se sucedieron y la expulsión de aquellos foráneos se consumó pero las leyendas permanecieron y ratificadas por algunos de ellos ya mencionados (Raleigh y La Condamine entre otros).

Así pues, se había vislumbrado más que descubierto la desembocadura del Amazonas, se había llevado a cabo una urgente, en exceso, travesía del gran río y, al hacerlo,

$9 \mathrm{Su}$ curso alto tiene un desnivel que, rápidamente, baja desde los 4.700 a los $200 \mathrm{~m}$. de altura lo que imprime a sus aguas una velocidad considerable, sin embargo, desde territorio peruano, a lo largo de todo el Brasil actual su lentitud es grande por una pendiente inapreciable. Todo contribuye a la enormidad de sus inundaciones, al desarrollo de insospechadas mareas, que dé lugar al formidable pororoca. Un espacio uniforme en temperaturas, elevadas, que origina una selva húmeda majestuosa que sostiene una flota y fauna paradisíaca, una reserva de la Humanidad. Una red fluvial de más de mil ríos que erosionan y arrastran gran cantidad de materiales en suspensión y otros muchos sólidos peligrosos para la navegación en algunos afluentes.

10 Los españoles dedujeron que vivían lejos del cauce, a siete jornadas, y hablaron de otros pormenores sobre su organización y modos de vida (sin convivencia con hombres en sus pueblos, trato diferencias a hijas e hijos, construcción de vivienda, tejidos y adornos de oro y otros materiales, etc.).

11 Relación que escribió...del nuevo descubrimiento... que descubrió, por muy gran ventura, el capitán Orellana... con LVI hombres. Manuscrito de la BN de España, ed. en M. CUESTA. La Amazonia, pp. 95-153. 
se había cruzado el continente sudamericano por su mayor dimensión longitudinal, a la altura de la línea ecuatorial. El río Amazonas, el espacio amazónico, espectacular y amenazador apareció ante aquellos hombres que navegaban en embarcaciones construidas por ellos mismos y a las que denominaban pomposamente bergantines. El curso fluvial, el gran territorio quedaba de manifiesto más por lo que se intuía de extraordinario, que por lo que se percibió, como mínimo, había sido desvelado y descrito todo un mundo inquietante y atractivo.

Se produjo una segunda expedición; una de las más lamentables desarrolladas por el hombre en aquella región. El viaje tuvo más de epopeya que de exploración; en él se originó una mezcla de vivencias sobre e infrahumanas hasta tal extremo que han sido numerosos los escritores, psiquiatras y guionistas de cine que se han sentido atraídos por aquella andanza y desventura mucho más que por la descripción geográfica o por las etnias pobladoras del territorio ${ }^{12}$.

Fue la expedición apouyada Andrés Hurtado de Mendoza, marqués de Cañete el Virrey de Perú, comandada por Pedro de Ursúa que concluyó Lope de Aguirre. Una lucida hueste integrada por hombres experimentados que se vieron abocados a vivir, convivir y sobrevivir en el medio amazónico, particularmente excitante, que exacerba todo tipo de pasiones en que las más bajas se hacen necesariamente patentes y todas confluyeron en aquella compleja tramoya que las autoridades de la época pretendieron borrar de la Historia. Muchos, la mayor parte de los conquistadores, habían quedado sin premio a sus hazañas. Tanto esfuerzo, tanto gasto, tantos peligros arrostrados, tantos servicios a lo largo de una y hasta dos décadas no había tenido recompensa; su aspiración de mejora social se había visto frustrada. Y por si todo ello fuera poco las Leyes Nuevas dictadas por la Corona contribuían a perjudicar en sus intereses a los que habían logrado algún beneficio en la empresa. Las tensiones sociales de los españoles en el Perú desencadenaron las denominadas Guerras civiles; el castigo y perdón a que dieron lugar contribuyeron a producir mayor desigualdad en el trato. El descrédito de las autoridades se incrementó y el descontento de los damnificados hizo que sus lenguas se soltaran expresando su irritación en público por mucho que el nuevo Virrey ejerciera su autoridad y castigara sin distinción a pobres y poderosos.

La tensión social hacía precisa la apertura de una válvula por la que se liberara la energía excedente; el objetivo atractivo la búsqueda de El Dorado; nada podía serlo tanto. La Relación de Francisco Vázquez ${ }^{13}$ fue la de la expedición de Ursúa, después, de Aguirre; la muerte de los propios españoles se iba sucediendo sin solución de continuidad, como declaró Álvaro Acuña en la Audiencia de Santo Domingo ${ }^{14}$. El mismo Aguirre escribió una extraordinaria carta a Felipe II en cuyo texto los dislates entremezclados con datos autobiográficos y verdades que se suceden con toda naturalidad.

12 Entre estos autores se hallan desde Tirso de Molina a Mozans, pasando por Ortigueira, Bayo, Palma, Sénder, Otero Silva y Torrente Ballester.

13 Relación de todo lo que sucedió en la xornada de Amagua y dorado que el gobernador Pedro de Orsua fue a descubrir con poderes y comisiones que le dio el bi Rey marqués de Cañete, Presidente del Piru. Trátase asimismo del alçamiento de don Hernando de Guzmán y Lope de Aguirre y otros tiranos. Manuscrito de la BN. en M. CUESTA: La Amazonia, pp. 153-247.

14 Mató e hizo matar el dicho Lope de Aguirre a...treinta y seis personas y en la [isla] Margarita los seis que dicho tiene y en tierras venezolanas prosiguió la nómina en la que hay que incluir a su propia hija y hasta provocó la muerte propia. 


\section{Explorando el Amazonas en ambos sentidos}

Surgieron otros protagonistas que tenían diferente mentalidad, nuevos métodos y otros objetivos, que no anhelaban riquezas ni grandes honores y sin embargo alcanzaron frutos análogos: aumentaron territorios para la Corona, incrementaron el número de súbditos para el rey y de almas para su Dios. Se demostró que eran excelentes exploradores para tan intrincado espacio. Uno o en grupos de dos o alguno más, se adentraron con frágil agilidad y autosuficiencia y eran vistos hasta con simpatía por los grupos receptores aunque tampoco estuvieron exentos de reacciones exterminadoras.

$\mathrm{Su}$ actividad era eclesiástica, proselitista, pero su legado documental (relaciones, cartas, crónicas, mapas) es muy rico en información geográfica (ríos, lluvias, patrón de asentamiento, modos de producción, transporte, etc.) y antropológica (vocabulario, organización social, ritos y creencias, vestimenta, armas y herramientas, etc.), que se incrementaba con una acción transculturadora y por los avances que imprimieron a las comunicaciones (trazado de trochas que disminuían a catorce días una distancia que se tardaba en recorrer dos meses). Estos peculiares exploradores reconocieron, especialmente, la cuenca alta del Amazonas, en los Andes Centrales, y la "ceja de la montaña", abrupta ladera andina hasta la inconmensurable llanura amazónica.

Realidades, mitos y leyendas seguían atrayendo a laicos y clérigos por distintos intereses; el jesuita Font mostraba su interés por la región del alto Amazonas, de la montaña selvática peruana, y por los habitantes de las islas "ricas" del río Marañón. Un espacio particularmente llamativo era el ocupado por los aguerridos y temibles indios jíbaros, unas tierras que presumible aunque infundadamente debían poseer anheladas riquezas. Sobre ellas confluyeron los intereses de varios expedicionarios, en el último (1619) Diego Vaca fundó San Francisco de Borja en la ribera del Marañón. Fue el germen de la gobernación de Mainas y el impulso a la prosecución misional hasta alcanzar el Pongo de Manseriche. Se realizados muchos intentos para ampliar los horizontes geográficos pero sobre todo hay que subrayar las fundaciones jesuitas y franciscanas, bien documentadas. En 1586 los franciscanos tenían 12 conventos que eran 117 puntos doctrinales en 1635 en territorio de los indios cofanes, omaguas, encabellados, avijiras y maynas. Los dominicos y jesuitas también hicieron grandes contribuciones a las exploraciones, conocimiento y difusión de realidades e interpretaciones geográficas y etnográficas de grandes regiones marginales.

Entre aquellos frailes hay que resaltar a Domingo de Brieva y Laureano de la Cruz. El primero por protagonizar la travesía de América del Sur por su máxima dimensión en el sentido de los paralelos y -lo que es excepcional- en viaje repetido de ida, vuelta y retorno, una triple trayectoria consecutiva que encierra una múltiple dificultad y peligro aunque en el siglo XXI se hubiera considerado una hazaña deportiva y aventurera. Es evidente pues que el viaje de Domingo de Brieva fue indudablemente extraordinario y, sobre todo, de especial estímulo para la proyección portuguesa, en dirección contraria, desde la desembocadura del Amazonas hacia el interior continental.

Alertados los portugueses por la llegada de gentes españolas procedentes de Quito se prepararon para remontar el Amazonas, ampliar su conocimiento del espacio y sobre todo el territorio a ocupar a la vez que cortaban el acceso a sus competidores españoles. Para los portugueses los condicionantes físicos del medio les facilitaba su ampliación 
de horizontes geográficos remontando el río en dirección Este a Oeste; efectuaron varias expediciones y pudieron incorporar los puntos estratégicos de las confluencias fluviales con el Amazonas de los ríos Negro, Japurá, Napo, Içá, Branco, Xingú, Tapajoz y Solimoes. Las acciones más significativas, desde los inicios, fueron las de Diogo Nunes (1538) al país de Machicaro, el ensayo de Simao Estácio da Silveira para abrir una vía fluvial, navegable, al Perú, la expedición de Luis Aranha de Vasconcelos (1623) por el curso del Amazonas y la de Mendes de Morais (1730) al Napo, sin contar las de Teixeira y del famoso bandeirante Raposo Tavares.

Pedro Teixeira con 70 ó 75 soldados más los cuatro españoles que habían descendido por el río, 900 indígenas (se ha afirmado que su número ascendió a más de dos mil) y con abundantes medios realizó una travesía que ha estudiado M. J. Guedes ${ }^{15}$ : río Pará hasta Carnapijó, Marajó y Marapatá hacia el Tocantins para llegar a un estrechamiento susceptible de fortificación, según los españoles, donde se asienta hoy la ciudad de Obidos; prosiguieron navegando por la margen derecha hasta los tupinamba donde Teixeira recibió noticias de las famosas amazonas, que no vieron, y cruzaron ante la desembocadura del río Madeira; franquearon ante el Negro ascendiendo por su curso y apreciando sus calidades físicas y organolépticas. Superaron la desembocadura del río Cuchiguará (Purús) hasta Cutuá y río Tefé. A continuación, ya en territorio Omagua, sobrepasaron el río Juruá (o de las Barreras); después el Jutaí (o río del Cuzco) y el Javari en una navegación que iba dificultándose progresivamente. Desde allí Teixeira envío un núcleo de avanzada que alcanzó Quito, dando por concluido el primer viaje que remontaba el río Amazonas, en el que la participación del padre Brieva fue decisiva.

Evidentemente, al ser el tercer viaje en cruzar la distancia Quito-Belém las aportaciones antropológicas, geográfico descriptivas, cartográficas, fueron más ricas y precisas que las ofrecidas por los cronistas de las expediciones de Orellana y Ursúa/Aguirre y su repercusión en otras obras es apreciable. Por otra parte las facilidades, aprovechadas, que daba a la expansión portuguesa en la Amazonia permitió, andando el tiempo, ejercitando la doctrina del uti possidetis, incorporar a Brasil la mayor parte de la Amazonia hasta dominar las extensiones que ahora tiene.

El Amazonas iba adquiriendo la categoría de vía de comunicación casi transoceánica. Sobre todo desde que el franciscano Domingo de Brieva repitió la proeza geográfica que había realizado Orellana y aún superándola ampliamente con sendos viajes de retorno y vuelta a navegarlo ${ }^{16}$. El padre Brieva alcanzó la desembocadura del Amazonas desde Quito, muy cerca de donde se pensaba que nacía el gran río ${ }^{17}$. Cruzar la cordillera andina y descender casi al nivel del mar y navegar durante miles de kilómetros por el río hasta el océano entrañaba no solo dificultades sin cuento sino problemas y penalidades imponderables. El impacto entre los portugueses tampoco fue desdeñable; el gobernador envío a un grupo explorador bajo el mando de Pedro Teixeira para acompañar al fraile hasta Quito; en verdad para reconocer el territorio, para verificar la posibilidad de acceso hacia tierras occidentales, altas, en región equinoccial, llena de posibilidades. Acuña canta sus excelencias, Brieva muestra la vía de acceso, Brieva con Teixeira veri-

15 GUEDES, Max Justo: “Aspectos náuticos da viagem de Pedro Teixeira”, en Revista de Cultura do Pará. Ano 6, n 22 e 23 (1976), pp. 39-87.

16 Ibídem.

17 ACUÑA, Cristóbal de: Nuevo descubrimiento del Gran Río de las Amazonas. Madrid, 1891. 
fican el camino desde las bocas del Amazonas y, por si fuera poco, se traza el más bello mapa de tamaña red fluvial ${ }^{18}$.

Ciertamente las ingentes dificultades para los españoles del virreinato peruano, del reino de Quito, hacían casi imposible el crecimiento hacia el Este; las grandes facilidades que ofrecía el gran río como vía de comunicación permitían el crecimiento del Brasil luso hacia el Oeste. Las dificultades permanecieron vigentes y recogidas por la cartografía hasta la confección del mejor mapa, "maldito", de América del Sur realizado por Juan de la Cruz Cano y Olmedilla, el gran cartógrafo de gabinete ${ }^{19}$.

Aquella red fluvial, el denominado "Marañón español" quedó reflejado entre otros, en el mapa "trazado en las cárceles de Lisboa" por el P. Francisco Javier Weigel ${ }^{20}$; con una línea de límites señalada con cruces blanca para indicar el de los franciscanos y de puntos donde continúa la de los jesuitas, en la divisoria de aguas entre el río Putumayo y Napo y por el río Yavari; al otro lado del límite, entre 4 y $7^{\circ} \mathrm{S}$ y 48 y $50^{\circ} \mathrm{O}$, se lee "colonia lusitanoorum" para designar, obviamente, al Brasil portugués.

\section{Otros exploradores y viajeros}

La fugaz visión de la desembocadura del Amazonas (Pinzón) y las dos azarosas travesías de Orellana y de Aguirre transmitieron una imagen amazónica de enmarañamiento, inmensidad y pobreza. Otros protagonistas con características diferentes (jesuitas y franciscanos) hicieron progresar el conocimiento geográfico y etnológico de la amazonia con lentitud pero con entusiasmo sobre la cuenca alta durante los siglos XVI y XVII y aún en tiempos posteriores. La cartografía lo recoge (D'Abbevill y el mapa de la Biblioteca Nacional de Madrid, el de Brieva ${ }^{21}$, como ejemplos).

Esta trayectoria eclesiástica se consolidó en el XVIII cuando en 1707 el padre Samuel Fritz grabó un buen mapa amazónico fruto de sus 16 años de trabajos. A partir de mediados del "siglo de las luces" hacen su aparición los científicos, entre ellos La Condamine (recorrió el Amazonas y realizó un mapa) y los comisarios de la fijación de límites entre España y Portugal precisamente en aquel territorio ${ }^{22}$.

Así pues, el primer tanteo en profundidad importante fue la de Francisco de Orellana que describiera el dominico Gaspar de Calvajal, análoga pero muy luctuosa fue la

18 CUESTA, M.: Amazonia, pp. 320-321.

19 Objeto de la tesis doctoral de J. A. Jiménez Garcés. UCM. Madrid 2012.

20 Impreso por Hauser y Menet, Madrid.

21 Biblioteca Nacional. Ms. 5859.

22 Durante el XIX la atracción del Amazonas se generalizó. Los nuevos países amazónicos y los luso brasileños realizaron expediciones exploradoras a la par que viajeros de países lejanos visitaron la región en una mezcla de búsqueda de aventuras, afán de curiosidad, atracción por la observación e interés ciencia que los llevó a difundir datos no exentos de fantasía, noticias con notas fabulosas, dibujos con imágenes exóticas y mapas contribuidores de progreso. Se citan algunos nombres, Spix y Martins (1819-20) y el marino Manso (1827) realizaron viajes de observación por el Amazonas que fueron proseguidos por el naturalista Poepping (1832), Wallace (1847), Bates (1848), Ave-Lallemat (1859) y Marcoy y otros. Enseguida se efectuaron expediciones sistemáticas en la red fluvial y el territorio: Acevedo, Pinto y Chadles, 1869, hasta el río Beni; Orton, hasta las cabeceras del Napo; Crevaux, desde Venezuela, el colombiano Reyes, etc. Especial atención a los afluentes: Tucker en el Ucayali, Wertheman y Sánchez entorno al Ené y Huallaga, Séller al Madera [sic] y Purús, Brown al Madera, Heath al Beni, Fizcarraldo al Ucayali y Beni, además de Peyer, Wlenir, Monier, Ehrenreich, Katzer, Condreau, Huber, Goeldi, Pando, Viellerobe, Cruls, Pesce, etc. En general unos viajes de exploración geográfica donde se mezcla la política, la ciencia y la aventura, como dice Ângela Domingues y donde tuvieron su sitio La Condamine, ya citado, y Humboldt; donde brillaron cabalmente los Rodríguez Ferreira y Debret; en el siglo XX el proyecto fallido del español Iglesias Brage. 
de Lópe de Aguirre ${ }^{23}$; no sirvieron más, y no es poco, que para evaluar la magnitud y disposición de América del Sur a la altura de Ecuador, precisamente por la parte más extensa. La explicación que dieron fue tan pobre en las explicaciones como escasa en noticias geográficas. Más amplias fueron las aportaciones de Jacinto de Carvajal sobre la cuenca del Orinoco, también siguiendo el curso de las aguas, en un tramo más corto y cuando había transcurrido un siglo. Más numerosas fueron las interpretativas de la cuenca del Plata, remontando sus aguas, por su situación estratégica como posible paso hacia el Pacífico, primero, o como eventual acceso al Perú argentífero, de inmediato.

\section{LA REGIÓN ORINOCO-GUAYANESA}

Numerosas capitulaciones e instrucciones conservadas en el Archivo General de Indias testimonian las particularidades de los protagonistas, su formación y anhelos, sus virtudes y defectos, sus logros y servidumbres, sus enfrentamientos, su enriquecimiento, gastos, ruina, alianzas, premios y final. Una de la aventura más notable fue la búsqueda del paso hacia la Especiería. En el istmo centroamericano, en el norte del continente sudamericano (Fernández de Oviedo, Diego Caballero y un nutrido grupo de descubridores y émulos). En el resto de la costa hasta lograr el éxito con Magallanes. Pequeñas islas habían servido de instrucción en búsqueda de asentamiento, riquezas y fracasos; Margarita y su entorno, especialmente el asentamiento de Nueva Cádiz ${ }^{24}$ ofrecieron algún éxito. Trinidad, presumible llave del Orinoco, tampoco se mostró más seductora y célebre que exitosa.

Diego de Ordás y Jerónimo de Ortal jugaron su papel en aquellos territorios tan poco definidos que sus aguas se entremezclan con las del Amazonas. Pero siempre con algún indicio y hasta certificación de estímulos económicos más allá de iniciales y frustrados esfuerzos. Ordás se internó 600 millas náuticas por el Orinoco arriba; fracasó en sus objetivos pero, como en otras latitudes, habla de una atractiva tierra de Meta, un nuevo "Perú", justamente al sur del espacio conocido como Tierra Firme, al Este del mundo andino, donde las leyendas van creciendo y emergen -así lo recoge Fernández de Oviedo- tierras de amazonas. Unas riquezas que causaron mella en banqueros alemanes hacia un Dorado en las tierras de Meta que, pronto se situó, en el altiplano bogotense y se plasmó en elemento señero de una región tan rica que el polvo de oro constituía el principal maquillaje del personaje; uno de los poblados se pensaba que era el no menos legendario de Manoa. Una leyenda, personaje y ciudad, móvil en su búsqueda sobre el terreno, en su localización cartográfica, en las ansias de exploradores (Belalcázar, Fernández de Serpa, otros más citados, anteriores o posteriores.

Así como siempre cabe el recurso de investigar sobre la isla de Margarita con respecto a las Guayanas ${ }^{25}$, del mismo modo es pertinente esclarecer la relación entre la isla de Trinidad y las bocas del Orinoco, pero lo cierto es que el Dorado tenía, como el Preste Juan, la isla de San Borondon o de Brasil y tantas leyendas y mitos, al menos,

23 JOS, Emiliano: La expedición de Ursúa al Dorado, la rebelión de López de Aguirre y el itinerario de los "marañones". Huesca, 1927. Sigue siendo uno de los trabajos más interesantes sobre el tema.

24 OTTE, Enrique: Las perlas del Caribe: Nueva Cádiz de Cubagua. Caracas, 1977.

25 La bibliografía es muy abundante. Ver, por ejemplo, DONIS RÍOS, Manuel Alberto: Evolución histórica de la cartografía en Guayana y su significación en los derechos venezolanos sobre el Esequibo. Caracas, ANH, 1987. 
algunas notas de errante o una geografía andariega que decía Pérez Embid. Algo parecido sucedió con la ciudad o, mejor, poblado de Manoa.

Los españoles, en la segunda mitad del siglo $\mathrm{XVI}^{26}$, insistieron en el control de aquellos territorios pero también otros europeos, empeñados en dominar puntos estratégicos en la costa atlántica, fijaron su atención en un Dorado, real o fantasma, pero cierto es que la navegación remontando el Orinoco presentaba dificultades insalvables en los raudales antes de alcanzar eventualmente la ciudad de Manoa en la Guayana que Raleigh $^{27}$ describió en los años finales del siglo XVI, no muy lejos de las aguas de un afluente del Amazonas que venía a enlazar con el lago de Parima. No faltó quien afirmara el valor estratégico de las bocas del Orinoco como vía de acceso al Perú.

El siglo XVIII se mostró particularmente activo en el avance portugués y en el intento de detener el progreso por parte de los españoles; misioneros y pequeños destacamentos guerreros hispánicos eran insuficientes en una geografía majestuosa y formidable. Dorados, manoas y parimes siguieron como centro de atracción; afluentes del Orinoco y del Amazonas jugaron su rol respectivo en españoles y portugueses; la unión de ambas cuencas, el Caño Casiquiare, tuvo un relevante papel secundario que el propio Alexander von Humboldt, recogiendo noticias de misioneros españoles, llegó a apreciar ante la cólera portuguesa ${ }^{28}$. Era una región de tensión hispano portuguesa.

Pero ya estamos en una época luminosa; los propios eclesiásticos estaban dispuestos a buscar junto a explicaciones clásicas ${ }^{29}$ otras menos crédulas todo lo cual no obsta para que sigan perviviendo viejas leyendas, como la de las amazonas ${ }^{30}$ que también aceptaba el padre Gilij ${ }^{31}$. La Condamine ${ }^{32}$ lo rechaza sin ambages y Humboldt con contundencia.

26 Recuérdense las capitulaciones otorgadas a Jaime Rasquín (1557) para una gobernación en el Río de la Plata, la concedida a Diego de Vargas (1559) para la desembocadura del río Amazonas, la de Lucas Vázquez de Ayllón (1562) para la Florida, la de Pedro Menéndez de Avilés (1656) para la costa oriental de América del Norte, la de Jorge Quintanilla (1565) para la búsqueda del paso, la de Diego Hernández de Serpa (1568) para la Nueva Andalucía [cuenca del Orinoco desde sus bocas hasta el Amazonas], la de 1568 para Pedro Maraver de Silva (1568) para la Nueva Extremadura [entre Perú, Río de la Plata y Nueva Andalucía], la de Juan Ponce de León (1569) para Trinidad y Tobago, la de Juan Ortiz de Zárate (1569) para la gobernación del Río de la Plata [para drenar el comercio del Perú], la de Diego de Artieda (1573) para Costa Rica [y comunicar ambos mares], una nueva capitulación de Maraver de Silva (1574) y la de Juan de Viloria Ávila (1574) para hallar el paso por el Darién.

27 RALEGHEQUITEM, Gualtherum: Brevis et admiranda descriptio regni Guianae, auri abundantissimi, in America, sev Novo Orbe, sub línea aequinoctilia siti, quos nuper admodum, annis nimirum 1564, 1595 et 1596. Noribergae, MDXCIX. [UCM. BH. FG 2731].

28 CUESTA, M. y S. REBOK (coord.): Alexander von Humboldt. Estancia en España y viaje americano. Madrid, RSG y CSIC, 2008.

29 GUMILLA, José: El Orinoco ilustrado y defendido: historia natural, civil y geographica de este gran rio y de sus caudalosas vertientes, govierno, usos y costumbres de los indios sus habitadores. Madrid, por Manuel Fernández..., 1745. [UCM.BH. FG 2482; UCM.BH. FLL 35049; UCM.BH. MED 12394].

30 RIVERO, José: Historia de las misiones de los llanos de Casanare y los ríos Orinoco y Meta. Bogotá, 1956.

31 GILIJ, Filippo Salvadore: Saggio di storia americana o sia Storia naturale, civile, e sacra de regni, e delle provincie spagnuole di terra-ferma nell' America meridional / descrita dall' Abate Filippo Salvadore Gilij...; Tomo I, Della storia geografica, e naturale, della provincia dell'Orinoco. Roma, per Luigi Perego Erede Salvioni..., 1780 [UCM.BH. FG 2488].

32 LA CONDAMINE, Charles-Marie de: Relation abrégée d'un voyage fait dans l'intérieur de l'Amérique Méridionale. Depuis la côte de la Mer du Sud, jusqu'aux côtes du Brésil \& de la Guiane, en descendant la riviere des Amazones; lûe à l'assemblée ces, le 28. Avril 1745. Avec une carte du Maragnon levée par le même. Paris, veuve Pissot, 1745. [UCM.BH. DER 15528]; otra edición posterior en [UCM.BH. FLL 27743]; también en DAVIN, Diego: Cartas edificantes y curiosas escritas de las missiones estrangeras, y de Levante por algunos missioneros de la Compañía de Jesús; tomo 16. Madrid, en la imprenta de la viuda de Manuel Fernández, y del Supremo Consejo de la Inquisición, 1757. [UCM.BH.FG 2786, T. 16; UCM.BH. DER 12315, T.16; UCM.BH. FLL Res.145, T.16]. 
Sin embargo la presencia de la toponimia que recoge el Dorado, la ciudad de Manoa y el lago de Parime tuvo su reflejo en la cartografía y, por ende, su pervivencia secular.

Es la náutica fluvial que, sobre la vertiente atlántica, estaba estructurada por tres desmesuradas llanuras; en la pacífica por infinidad de ríos cortos -con excepción de la no menos compleja red del Guayas- pero con beneficioso aporte acuoso a pesar de lo mínimo des caudal, comparativamente. Unos y otros carentes de su aprovechamiento náutico. Los del Atlántico tuvieron sus ensayos de descubrimiento hidrográfico ${ }^{33}$. El Plata con su amplitud se ofrecía a los barcos que se asomaban a aquel mar dulce (Solís, Mendoza y otros iniciaron una etapa fundacional que fue desde lo efímero -primera Buenos Aires- hasta los asentamientos en la cuenca del Paraguay -Asunción 1541-). Los ríos eran el factor estratégico y logístico decisivo, también táctico.

El Magdalena parece mejor dotado para la navegación, pero en la primera mitad del siglo XVI y aún más adelante su aprovechamiento no fue destacable. Su desembocadura estaba nítidamente en región española; los puertos próximos, también por más que sufrieras ataques navales de otros europeos. Más dificultoso si cabe, por los condicionamientos del medio, fue el cauce del Orinoco para Ordás, Ortal y tantos otros que entraron por sus bocas o que accedieron desde la costa Caribe sudamericana; en el sentido del curso fluvial ya mencionamos al dominico Jacinto de Carvajal. Finalmente queda la gran cuenca amazónica, cuya desmesura fue percibida, en primera instancia por Orellana, ratificada por Aguirre y reiteradamente visitada por franciscanos (Domingo de Brieva, Laureano de la Cruz,...) o por portugueses (Teixeira...), quienes asentaron los principales establecimientos aprovechando las facilidades que la estructura geográfica les ofrecía. Una falta de dominación nítida española en un espacio escasamente definido que podía traducirse en centro de penetración náutica hacia el interior para potencias europeas ansiosas por establecerse en el las Indias.

Eran espacios inmensos drenados por ríos colosales que presentaban un descomunal territorio refractario al desarrollo urbano a su estructuración al estilo de grandes imperios indígenas o al europeo. Unas redes fluviales que facilitaban la entrada de navegantes situados en la desembocadura para remontar hacia el interior, no tanto a los situados en las cabeceras para descender al mar; pero con grandes dificultades superables en el descenso y difícilmente salvables en la remontada por causas de los raudales, pongos, avenidas difícilmente imaginables para los europeos de aquella época.

\section{TESTIMONIO CARTOGRÁFICO}

Toda esta trepidante actividad tuvo, como se sabe, un reflejo cartográfico abundante y reiterativo, erróneo y, a veces, intencionadamente distorsionado; los sistemas de proyección colaboraban en alguna medida a aceptar consideraciones de tal naturaleza. Pero además, la secular tensión hispano-portuguesa en su expansión ultramarina también tuvo alguna contribución puesto que el tema afectaba a la propiedad y posesión de territorios y al trazado de límites.

En cuanto a los perfiles costeros, el tratado de Tordesillas jugó un papel destacado. Nunca trazado sobre el terreno, se aceptaba que la línea meridiana pasara precisamente

33 CUESTA DOMINGO, Mariano: "Descubrimientos náuticos en el interior continental”, en Anais hidrográficos, tomo XLIX, suplemento (1992), pp. 8-95. 
por la desembocadura del Amazonas. Más al Sur, no se sabía; pero la clave estaba en que los mapas situaran la desembocadura del Río de la Plata al Este o al Oeste de la "línea". Si era dentro del ámbito portugués se cortaría el paso a las naves españolas y, consecuentemente, Portugal salvaguardaba su exclusiva ruta hacia la Especiería, al menos hasta el hallazgo de la Corona española de otro paso. Si la línea dejaba el Plata al oriente, el paso -conocido desde 1522- de barcos españoles estaba expedito hacia la Especiería. El conflicto de las islas Molucas entró de lleno en el problema ${ }^{34}$.

Mapas de distintas fechas mostrarán ambas posturas: el Juan de la Cosa (1500) no es significativo al respecto, pero en el denominado de "Cantino" (1502) se aprecia la tendencia a prolongar la costa hacia el Este; de forma más sobresaliente se percibe en los Piri Reis (1513) y Lopo Homem (1519), en Gaspar Viegas (1534), Sebastião Lopes (1549-1550), Desceliers (1550), Homem, Velho, Vaz Dourado; según las fuentes utilizadas, otros cartógrafos europeos de prestigio también mostraban una imagen pro-lusa: Ortelio, por ejemplo. Sin embargo, poco después del acuerdo de Zaragoza, los mapas de Diogo Ribeiro y de Alonso de Santa Cruz y Alonso de Chaves dejaban las bocas del Plata en territorio español, con un conocimiento suficiente y también en defensa de los intereses de su Rey ${ }^{35}$; otros portugueses y acreditados del resto de Europa también situaron las tierras sureñas, bocas del Plata incluidas en el ámbito español; era ya cuestión de conocimiento que la fecha de su realización no podía excusar: Gerard Walk (1645), el mapa del tratado de límites, el de Cano y Olmedilla (1775), etc.

Por lo que afecta a la imagen cartográfica del interior continental, las referencias al tratado de Tordesillas son muy frecuentes por lo que respecta a la Amazonia y los tratados de Límites; respecto a su trazado en los mapas, no se produjo. En cuanto a la dibujo de los mapas están caracterizados por una evolución desde lo que los historiadores del arte denominan "horror vacui" al conocimiento minucioso y detallado, pasando por los grandes vacíos ilustradores, algunas carencias persistentes y la pervivencia de rasgos que encuadramos entre los real, lo verosímil y lo imposible.

En otras facetas culturales y también en la cartografía, los gustos han oscilado frecuentemente entre la repulsión al vacío y el silencio como elemento ilustrador o conformador $^{36}$. Los mapas antiguos muestran los gustos de la época, el entusiasmo de los factores, el entusiasmo de sus artífices o la satisfacción de sus poseedores. Podría llegarse a una conclusión progresiva precipitada según la cual a mayores dosis de exactitud menores proporciones artísticas y viceversa. Así los portulanos o el mapamundi

\footnotetext{
34 CUESTA DOMINGO, Mariano: "La fijación de la Línea -de Tordesillas- en el Extremo Oriente", en El tratado de Tordesillas y su época. Valladolid, Junta de Castilla y León, 1997, vol. 3, pp. 1483-1518.

35 CUESTA DOMINGO, Mariano: Cartografía de Santa Cruz e Islario de Santa Cruz. Madrid, Real Sociedad Geográfica, 2003; del mismo: "Alonso de Santa Cruz, cartógrafo y fabricante de instrumentos náuticos de la Casa de Contratación”, en Revista Complutense de Historia de América [RCHA], vol. 30 (2004), pp. 7-40; Tres cartógrafos portugueses en la Corte del Rey de España; Ribeiro, Lavanha, Teixeira. Academia Portuguesa da História. Lisboa, 2010; A casa de contratación da Coruña. Santiago de Compostela, Xunta de Galicia, 2009. CUESTA DOMINGO, M. y SURROCA, A. (dir. y coord.): Cartografía hispánica. Imagen de un mundo en crecimiento. 1503-1810. Madrid, Ministerio de Defensa, 2010; CUESTA DOMINGO, M. y SURROCA, A. (dir. y coord.): Cartografía medieval hispánica. Imagen de un mundo en crecimiento. Madrid, Real Sociedad Geográfica y RLNE, 2009; CASTAÑEDA, P., M. CUESTA y P. HERNÁNDEZ: Alonso de Chaves y el libro IV de su 'Espejo de Navegantes'. Madrid, Ed. Deimos, 1977.

36 En la música el silencio puede ser considerado como una octava nota y juega un papel tan destacado como cualquier otra; es fundamental y ninguna composición sonaría igual con su interpretación o si estuviera suprimida de la composición.
} 
de Cresques (1375) como los mapas del siglo XVI recogidos en la Portugaliae Monumenta Cartographica constituyen ejemplos característicos de una cartografía que rellenaba con imágenes legendarias, mitológicas o sencillamente artísticas los espacios cuya configuración ignoraban; no había vacío alguno, era ese característico pavor al vacío que atiborraba de gallardetes, filacterias, ríos de curso ficticio, montañas puramente estéticas, paisajes que describen un mundo idílico de plantas, animales y hombres, riquezas sin cuento y exóticas. Por el contrario, en la cartografía de la Casa de la Contratación; las cartas universales de Diogo Ribeiro evidencian de forma genial lo que se ignora, lo que se halla "por descubrir" y "por conquistar", en terminología hispana de la época. Son silencios, vacíos a los que no se les achaca error; todo lo contrario, se les agradece la expectativa que ofrecen a que otro piloto rectifique, enriquezca o ratifique lo allí expuesto. Son silencios clamorosos acompasados por sistemas toponímicos.

En aquellas cartas lo verosímil se hallaba representado dando un grado de verosimilitud a los objetivos perseguidos: la búsqueda del paso, las fuentes de los grandes cursos fluviales, la expectativa de los grandes recursos, etc. Cuando se confirman las expectativas se pasaba a una representación de lo real con un nivel de certeza encomiable: la configuración continental, los grandes cursos y sus rápidos, la amplitud de las montañas y sus puertos, etc. Pero tampoco escasearon imágenes imposibles, como rastros de medievalismo en los mapas: girantes, patagones, singulares combates, animales desconocidos y hasta extravagantes.

\section{LA ESTRUCTURA FLUVIAL Y EL RECONOCIMIENTO CONTINENTAL EN EL ÁREA MÁS CONFLICTIVA}

Los factores comunes a las cuencas del Orinoco y Amazonas son su magnitud (sin entrar ahora a valorar su longitud o extensión), su difícil tránsito durante la Edad Moderna, el compartir algunas leyendas y hasta el estar unidos por un río que, a escala americana, es conocido como un simple "caño", el Casiquiare. Asimismo la reiterada mención al tratado de Tordesillas a nivel personal, al oficial y, especialmente, al diplomático hasta avanzado el siglo XVIII y aún después.

Existen además algunos elementos en la cartografía en los que se entremezclan objetivos que resultaron quiméricos con necesarias notas de verosimilitud que condujeron a tal grado de certeza infundada que hacen que su presencia en la cartografía perviviera durante siglos y persiste en la toponimia actual ${ }^{37}$. Los lagos de Manoa y Parime y Eldorado se sitúan próximos a áreas conocidas y a otras ignotas pero, en todo caso, se constituyeron en persuasivas y anheladas metas.

De igual modo, al observar los mapas (más allá de las descripciones de Fernández de Enciso, Alonso de Chaves, Gonzalo Fernández de Oviedo y demás) en un muestro por el elenco de mapas conocidos. En los manuscritos de la Biblioteca Nacional de

37 Por ejemplo, en el último gran atlas elaborado e impreso en España -el de Aguilar- En su Gran Atlas: la población de Manoa, en la confluencia de los ríos Madeira y Guapurá [354 D 16]; la Sierra Parima en el límite de Venezuela y Brasil, entre las fuentes del rio Branco o Parima y las del Orinoco, entre los 2 y $5^{\circ}$ de lat. N. discurre desde las fuentes del Orinoco hasta el raudal de Maipures. Asimismo Parima o Amacu hace referencia verdadero lago en la Guayana que, en época de lluvia, sobre una gran llanura en que se situó, frecuentemente, un lago imaginario donde se suponía existió la fabulosa ciudad de Manoa o El Dorado. [346 P 11, 354 E 6, 349 H 30]. 
España: el Islario de Santa Cruz, casi a mediado de siglo (XVI) sirve de testimonio de desconocimiento del interior continental ${ }^{38}$; en el Atlas de Juan Martínez, se coloca en la línea o meridiano las bocas del Amazonas y del Plata en tanto que el río Orinoco aparece en su mínima expresión. El Amazonas de una manera confusa y el Plata con una hipertrofia del estuario.

El mapa de Sebastiam Lopes (15 de noviembre de 1558), tiene un especial interés estético y una intencionalidad política de defender intereses de su Rey; no tiene inconveniente en situar banderolas hispanas sobre grandes espacios amazónicos pero coloca la Cruz de la Orden de Cristo sobre la cuenca del Plata. La imagen del Amazonas es geométrica, la del Río de la Plata con gran desarrollo del estuario, sin embargo no incorpora leyendas y mitos referentes a manoas, dorados, etc. aunque sí escenas de corta del palo de Brasil. De forma análoga sucede con el Atlas de Lopo Homem (1519) ${ }^{39}$ en cuanto a los adornos abundantes en la tierra brasileña, con escenas de corta del palo de Brasil, flora, fauna y alegorías indígenas y, obviamente, con la desembocadura del Río de la Plata exageradamente hacia el oriente del meridiano de la del Amazonas. El Brasil de J. Teixeira Albernaz (1631), acorde con las fechas, muestra un perfeccionamiento en el diseño litoral, también la red del Plata y desembocadura del Amazonas aunque con una excesiva proyección de la masa sudamericana hacia el oriente.

Los famosos atlas -también mapas sueltos- impresos de Blaeu, Janssonius u Ortelio utilizando fuentes ibéricas, particularmente hispánicas, trazaron sus brillantes mapas del área de nuestro interés.

Johanes Blaeu ${ }^{40}$ recoge en tres cartas la "Terra Firma et Novum Regnum Granatense et Popayan" (hojas 176-177) en las se muestra el río Atrato y la red Magdalena-Cauca, hasta el lago de Maracaibo. La vertiente caribeña o hacia los llanos de la Orinoquia capta las aguas del ramal cordillerano andino septentrional. Era un área en que la fatiga de las embarcaciones, la escasez y actitud de los hombres y la penuria de los medios a más de los perfiles de los cauces hacían que la navegación fuera el mejor método de transporte y comunicación. En el Pacífico, hasta el Esmeraldas, peor aún por la naturaleza del suelo y por las características generales y particulares del medio y de la población allí asentada. El mapa de "Venezuela cum parte australi Novae Andalusiae" (pp. 178-179) se halla que presentan el delta del Orinoco y su curso en un arco corto que baja hasta sobrepasar los $5^{\circ} \mathrm{S}$. Es el "Río de Paria, Yuyapari, Huria o Orinoque". En "Guiana sive Amazonum Regio" (pp.180-181) ofrece la imagen del territorio entre los ríos Orinoco, Amazonas hasta el Tapicuru. Cruzado por la Línea Equinoccial se halla un gran lago, el Parime, cuadrangular, con sendos riachuelos que ayudan al lago en su carácter endorreico de un gran territorio. En el ángulo NO del lago un asentamiento lleva el topónimo de Manoa o El Dorado. Finalmente, la hoja sobre "Brasil” (pp. 182-183), desde el río Amazonas hasta el de La Plata, con la lagoa dos Patos, convertido en un verdadero lago.

Joannes Janssonius ${ }^{41}$, en su gran libro que interesa aquí por sus láminas $5^{\mathrm{a}}$ y $6^{\mathrm{a}}$ (pp. 55-56 y 57-58 respectivamente): "Insula S. Iuan de Puerto Rico, Caribes... canibascuos

38 Lo que hemos denominado un vacío ilustrador en una carta de América del Sur aportulanada; con una línea costera expresada con minuciosidad toponímica. El Orinoco únicamente señalado por un apunte de delta y el interior con algunos apuntes orográficos situados por doquier.

39 Conocido como Atlas Miller. Ed. facsímil de A. Pinheiro Marques.

40 BLAEU, Johanes: Gran Atlas, siglo XVII. Madrid, Libsa, 1999.

41 JANSSONIUS, Joannes: Het vijfde Deel Des Grooten Atlas. Amsterdam, 1652. Sig. MN. AR-10192. 
insulae" ofrece la desembocadura del Orinoco pero ignora el interior continental salvo unos cerros decorativos. En la segunda, "Mar di Aethiopia vulgo Oceanus Aethiopicus", aparece América del Sur con un río Amazonas lineal, con orientación SO-NE, hasta el lago de los Xarayes. La hidrografía forma una verdadera red indefinida en que el río San Miguel (que desemboca inmediatamente al N. del río San Francisco) procede de un lago central (sin nombre, "Eupana") endorreico al que fluyen otros ríos además de otro que procede del lag. Xareyes; un lago que, por su parte, fluye al río Paraguay uniendo ambas cuencas que, mediante el Casiquiare ensamblaría eventualmente las tres grandes cuencas sudamericanas.

Abraham Ortelio ${ }^{42}$ en su Theatrum Orbis Terrarum (1573) que coincide en la fecha con las Ordenanzas para nuevos descubrimientos presenta una imagen estereotipada del subcontinente aunque con una exagerada deformación SO. Otros, como el "Nova et accurata totius americae tabula" $(1645)^{43}$ del mencionado Gerard Walk, ofrece una magnífica imagen de América incluyendo una proyección polar La carta merece un estudio monográfico pero aquí interesa subrayar algunas notas especiales: los cursos erróneamente diseñados de las tres grandes cuencas, la buena disposición de sus desembocaduras, la existencia del gran -desmesurado- lago de Parime, sobre la línea equinoccial y el nacimiento de los ríos Amazonas y del Paraguay en un mismo lago, obviamente, siguiendo direcciones opuestas, N-S. Sin embargo el mapa para el acuerdo del tratado de Límites $(1750)^{44}$ no presenta lago de Parime, ni el Dorado, aunque sí un gran lago en que alguno de los ríos que le aprovisionan de agua (río Paraguay) le hace enlazar casi directamente con la red del Amazonas a la par que en él mismo nace el gran Paraguay $\mathrm{y}$, por lo tanto, toda la red rioplatense.

En la segunda mitad del siglo XVIII militares y religiosos efectuaron algunas aportaciones que se perciben en sus mapas bien tomados de otros autores o bien de elaboración o adaptación propia. Las aportaciones geográficas sobre estos territorios ${ }^{45} \mathrm{se}$ muestran en la historiográfica jesuitas (José Gumilla y José Casani) o franciscanos (Antonio Caulín), incorporaron a su obra mapas. El de los dos primeros

En 1778 fray Antonio Caulín incorporó un "mapa coro-gráfico de la Nueva Andalucía, provincias de Cumaná y Guayana, vertientes del Orinoco, su cierto origen, comunicación con las del Amazonas, situación de la laguna de Parime y nuevas poblaciones" como reza la cartela el mapa está construido sobre las mejores observaciones y posteriores noticias por don Luis de Surville.

Siguiendo un orden cronológico pueden observarse algunos ejemplos: en 1779 el ingeniero Francisco Requena realizó el "Mapa que comprende todo el distrito de la Audiencia de Quito"46 en que se manifiesta individual y pormenorizadamente los pueblos indígenas que hay por el río Marañón y con algunas leyendas explicativas de circunstancias diversas:"el río Negro tiene muchas poblaciones portuguesas", "por estos dos

42 Centro Geográfico del Ejército, Madrid, apud CUESTA, M.: La Amazonia, p. 28.

43 Ibídem, p. 34.

44 Biblioteca Nacional, apud CUESTA, M.: La Amazonia, pg. 199. Un línea muestra el límite diferenciador de lo ocupado ("Misiones de jesuitas portugueses", "misiones de los carmelitas portugueses") y lo no ocupado (un espacio en que se aprecian algunos errores notables, como la situación de Moxos y Chiquitos, el Chaco).

45 CUESTA DOMINGO, M. y SURROCA, A.: Cartografía hispánica.

46 Centro Geográfico del Ejército, Madrid, apud CUESTA, M.: La Amazonia, p. 66. 
ríos, Iza y Yupura internan los portugueses para apresar indios" y, en el ángulo NE la famoso y grande lago Aparime recibiendo algunas aportaciones fluviales y alimentando el curso del amazónico río Negro.

En $1778^{47}$ O estado e capitanias do Grão Pará e río Negro, como as do Maranhao... muestra un buen conocimiento de la región aunque la frontera norte toma una postura sencilla al situar la Caribana hespanhola, la Terras dos holadezes y a Nova Guiana dos franceses. El río Casiquiari aparece situado en $309^{\circ}$ y $4^{\circ} \mathrm{N}$. Como se espera de la fecha -ligeramente posterior al mapa de Cano y Olmedilla- el diseño del interior continental de este territorio muestra la compleja red Orinoco-amazónica y otros cursos fluviales, especialmente, guayaneses. El "lago de Parime o mar Dorado, otros llaman mar Blanco" no tiene aquella magnitud ni forma geométrica antigua sino irregular de donde brotan $\left(1^{\circ}\right.$ lat. $\mathrm{N}$ y en $320^{\circ}$ long. $\left.\mathrm{O}\right)$ las aguas de un afluente del gran "río Parime o río de las Aguas Blancas".

En 1780-89, el matemático portugués Joze Joaquim Victorio da Costa, realizó la Carta geográfica das viajes feitas nas Capitanias do río Negro e Mato Grosso y sitúa el "Canal Casiquiari" en $4^{\circ}$ lat. $\mathrm{N}$ y $309^{\circ} 30^{\prime}$ ' long. E de la isla de Hierro ${ }^{48}$.

Un gran mapa firmado por Andrés Baleato $(1795)^{49}$ fue realizado merced a los trabajos durante quince años del padre Joaquín Soler; aún sigue mostrando los vacíos existentes en la cartografía continental. Se aprecia el curso del Río Marañón o de las Amazonas con sus tributarios por la derecha (río de la Madera, el curso imaginario del río Yavari y el río Ucayali). El Marañón, como indica en la leyenda explicativa nace en la laguna de Lauricocha. Desde poco más al oriente del Ucayali hacia el E. un gran rótulo indica "Píses incognitos" y una línea de puntos en dirección de los meridianos apunta: "Línea que deviera ser la división de límites de España y Portugal" ${ }^{50}$.

Mapa del Perú (1864) ${ }^{51}$ muestra muy bellamente los límites de la Amazonia con respecto a los países andinos, con una problemática diferente; las cuestiones de límites entre las repúblicas nacidas de los Reinos de las Indias prosiguen en el siglo XXI.

\section{El mapa de Domingo de Brieva}

Es justo y necesario hacer un énfasis exclusivo en un mapa manuscrito particularmente brillante que ya ha sido citado, el de la Biblioteca Nacional de Madrid ${ }^{52}$.

El viaje del padre Domingo de Brieva se inscribe en la actividad geográfico descubridora de los eclesiásticos en regiones "marginales"53. El viaje Quito-Pará y el de retorno ya acompañado con un destacamento portugués que capitaneaba Pedro Teixeira

47 CUESTA, M.: La Amazonia, pp. 48-49.

48 Ibídem.

49 Museo Naval, apud CUESTA, M.: La Amazonia, pp. 252-253.

50 En la cartela explicativa, Baleato expone su opinión al Virrey Francisco Gil y Lemos, que lo había mandado confeccionar.

51 Centro Geográfico del Ejército, Madrid, apud CUESTA, M.: La Amazonia, p. 42.

52 Sig. Ms. 5859. Ver JIMÉNEZ DE LA ESPADA, M: "Viaje del capitán Pedro Texeira aguas arriba del río de las Amazonas (1638-1639). RSG. Madrid, 1889; GUEDES, M. J: "Aspectos náuticos da viagem de Pedro Teixeira”, en Rev. de Cultura do Pará, ano 6, n 22 e 23 (Janeiro/julo, 1976), pp. 39-89; CUESTA, M.: La Amazonia, pp. 309-338, con facsímil del mapa; y "La BNE, centro de referencia americanista. Un caso", en C. Alvar (coord.): Encuentro internacional de hispanistas. Madrid, Biblioteca Nacional de España, 2012. 53 CUESTA DOMINGO, M.: "Mapas eclesiásticos, de la improvisación a la ciencia”, en CUESTA DOMINGO, M. y SURROCA, A.: Cartografía hispánica, pp. 333-386. 
dieron lugar al manuscrito de Madrid y a otro del propio Teixeira que se halla en Lisboa $^{54}$. El viaje de retorno a Quito del grupo hispano-portugués ha sido anotado líneas arriba. Unos 900 remeros en 45 grandes canoas ${ }^{55}$.

El texto en que el mapa se inserta es de las autoridades españolas en la región Andina para su Rey; en él se sintetizan las descripciones y relatos de los viajeros, e incorpora un bellísimo mapa que resulta ser el más atractivo del Amazonas y el más interesante de todas la época colonial; la comparación con otros le eleva tanto desde el punto de vista artístico como desde el técnico.

La información del viaje, revisada por Guedes, es la de verdadero descubrimiento y reconocimiento del Amazonas a lo largo de su curso en su trayecto ecuatorial ${ }^{56}$. La lectura del mapa sugiere que la información fue múltiple pero esta carta fue realizada por algún artífice español. La lectura de la toponimia, cartela, comentarios y ornamentación así lo justifican.

En el fragmento primero: está dibujada -en el corredor interandino- de forma estereotipada la ciudad de $Q V I T O^{57}$ y existe otro topónimo del que únicamente queda algún rastro. En el descenso hacia el cauce del gran río algunas inscripciones: Tiene este Rio de largo 1600 leguas, e inmediatamente, más al Este, Por aquí salió el armada de los Portugueses. Los afluentes del Amazonas que aparecen rotulados por la derecha son el Río de Archidona y el Río de Tunguragua ${ }^{58}$; por la izquierda el Río de Coca $^{59}$. Asimismo las comarcas que se indican son la Provincia de los Encabellados y Provincia ( $s i n$ nombre por desconocer el de los indios pobladores). Como se indica en el ms. de Madrid, los números son o bien de distancias en leguas $(80,85,70)$ o, dentro del río, de profundidad en brazas $(8,15)$.

En el fragmento segundo se produce una alteración (profundidades dentro del río, distancias entre el Ecuador y el cauce) al plasmar las distancias y profundidades y la escasa toponimia hace referencia, por la derecha, a la Provincia de Magua [Omaguas], Río del Cusco, Provincia y Provincia y Rio del Cusco [sic] además de otra Provincia innominada. Por la izquierda: Rastros de Provincia, Provincia del Rio Negro y el propio Río Negro $^{60}$ (extraordinariamente grande y profundo, de agua no potable -ni entonces-, color de azabache que recibe afluentes de aguas claras y consumibles).

Fragmento tercero: Provincia, innominada; Río de la Madera (muy caudaloso y

54 Biblioteca de Ajuda, códice: 51-V-41. Relazion... deel río delas Amazonas. Asimismo interesa también: Pérez de Salazar, Alonso: Carta manuscrita énque dá quenta, dela entrada de los portugueses, por el río Napo âla governazion delos Quijos. 1638.

55 Hasta dos mil formaba el total de los expedicionarios según REIS, A.C.F: "Paulistas na Amazònia e outros ensaios", en Rev. do Instituto Histórico e Geográfico Brasileiro, n 175 (1940). La descripción sobre la manera de construir aquellas embarcaciones en el ms. de la BN. de Madrid, ed. de CUESTA, M.: La Amazonia. 56 En el ms. de Madrid no duda de que el nacimiento del gran río se halla próximo al Cuzco o a Potosí por lo que debería tener una longitud superior a las 2.500 leguas. CUESTA, M.: La Amazonia.

57 Capital alcanzada desde Ávila, a pie, en "tres días de mal camino" decía Laureano de la Cruz, CUESTA, M.: La Amazonia, pg. 247-307.

58 Según Guedes, era la confluencia del propio Marañón y el Napo. El río de los Encabellados sería el Santa María; el Aguarico sería el Real de San Francisco.

59 El 27 de febrero se hallaban ya pasando ante el río Napo, Aguarico, Coca, Payamino, diez leguas abajo en el puerto de Archidona (en el Napo), no pudiendo atracar tornan a Payamino y puerto Nini. Se hallaban a tres días de mal camino de Ávila que decía fray Laureano de la Cruz. Desde allí, a pie, alcanzaron Quito, vía Guápulo, el día 24 de junio de 1638.

60 Según noticias de un piloto a través de informantes indios es un curso fluvial que uniría las dos grandes cuencas a las que vierte sus aguas: el Negro propiamente dicho, hacia el Sur, y la trayectoria septentrional sería el Orinoco mismo (CUESTA, M.: La Amazonia, p. 315). 
profundo, de agua muy fría, de color de barro que arrastraba numerosos árboles), Río de Tupinambas, Provincia de Tupinambras ${ }^{61}$. Por la izquierda, ningún topónimo.

Fragmento cuarto: más detallado por lo complejo de la desembocadura del gran río, por lo interesante de la información hidrográfica, por la información fidedigna portuguesa ${ }^{62}$ : por la derecha: Provincia de Trapajosos, Río Parnaiba [Xingú], Fuerte de Curapâ, Río Pancasa, Río Inguapi, Toquanti cornotâ, Mosu, Acarâ, Pará, Puerto de la Miel. En la desembocadura: Aroanas, Ninguna Puerta, Iapayas, I. Jauro?, Anchura de boca 80 leguas, Arbanas. Por la izquierda: Ilegible, Angostura de media legua y ay desde la barra a ... 300 leguas, ancho 3 leguas, Río de Curupilla?, Río de Olimpago?, Río de Tuare, Río Xaguanica, Río de la Sed, Río del Flechado, Río Cuerda Grande?, Río Araguari, Río Aranan?, Cabo del Norte.

Y fragmento quinto: Cabo de San Luis (con dibujo estereotipado de la ciudad), Río del Marañón, Desde las orillas del mar, hasta las tierras de Quito, por una y otra parte, son innumerables las Prouincias que ay, que por ser tantas y no saberse los nombres de todas, no se ponen aquí. Finalmente, en el ángulo inferior derecha, se distingue un escudo heráldico con la inscripción: ARMAS DE LA CIVDAD DE QVITO.

\section{A MODO DE CONCLUSIÓN}

Puede aceptarse que la configuración litoral y la conformación estructural de América del Sur fueron condicionantes en el proceso de descubrimiento, exploración, ordenación y reordenación del territorio durante la época hispánica; en la vertiente atlántica, fueron determinantes.

El tema de leyendas y mitos, que tanto influyeron en la etapa de intuición y conocimiento del espacio, quedó grabado en la toponimia y, con algunos cambios, perviven en la realidad de algunas regiones. La cartografía constituye un elemento definidor.

Desde hace dos siglos hasta la actualidad el papel jugado por la Cartografía y por la Geografía históricas ha sido de marca mayor. En tiempos de la independencia y durante la era de los estados iberoamericanos ha pervivido su interés e importancia; la necesidad de conocer, de descubrir y explorar, todo el territorio englobado dentro de los limites de sus respectivos países en la Independencia hacía imprescindible el estudio de aquellos mapas y relaciones. Cuando el trabajo fue hecho con deficiencia o egoísmo, dieron lugar a contenciosos que no han concluido.

61 Que describe el padre Acuña como indios aguerridos que usan veneno en las flechas y se hallaban refugiados frente a los portugueses en una isla, la de Serpa, según Guedes.

62 No en balde es el lugar donde se hicieron los preparativos de la expedición que iba a remontar el Amazonas; lo que exigió muchos días de trabajo: desde el 25 de julio de 1637 que parten de Belém hasta el 5 de septiembre que lo hacen de Cametá en el río Tocantins. Habían entrado por la "vía normal" o "por dentro" (R. Pará, bahía Guajará, Carnpijó, Marajó, Merapatá); los preparativos en Parijó duraron hasta el 28 de septiembre. A continuación avanzaron -Guedes- por la bahía das Bocas, estrecho de Boiuçu, furos de Tajapur y Limão, canal de Vieira, Gurupá, hoz del Parnaiba y R. Tapajoz [Río de las Clarísimas Aguas], donde fray Andrés de Toledo denominaba barbarrojas a los indios (por el trato que le infringieron). 